\title{
Qualidade fisiológica de sementes de gergelim em função do equilíbrio higroscópico em diferentes sais
}

\author{
Beatriz Fernanda Silva Lima ${ }^{1}$, Tanismare Tatiana Almeida ${ }^{*}$, Andréa dos Santos Oliveira ${ }^{1}$, Gustavo Lima \\ Machado $^{1}$
}

\begin{abstract}
RESUMO: O presente trabalho teve por objetivo avaliar a qualidade fisiológica de sementes de gergelim após seu equilíbrio higroscópico em diferentes condições de umidades relativas. A pesquisa foi desenvolvida no Laboratório de Fitotecnia da UNEMAT, Cáceres-MT e no Laboratório Central de Sementes da Universidade Federal de Lavras, LavrasMG. Utilizou-se sementes de gergelim da cultivar BRS Seda, sendo que para alcançar o equilíbrio higroscópio foram utilizados sais que proporcionavam diferentes umidades. O teor de água das sementes foi determinado pelo método estufa, com 2 repetições de 2 gramas, a germinação foi conduzida em 4 repetições de 50 sementes por tratamento, já as demais avaliações, testes de condutividade elétrica e tetrazólio, foram conduzidos com 4 repetições de 25 sementes por tratamento. O delineamento utilizado foi inteiramente casualizado com cinco tratamentos, onde as médias foram comparadas por meio do teste de Scott-Knott a 5\%. Pode-se observar que não houve diferença na germinação e na condutividade elétrica para os tratamentos propostos, demonstrando que as sementes apresentavam uma qualidade semelhante no que diz respeito a integridade de suas membranas. As umidades 3,49\% e 19,37\% favorecem a viabilidade das sementes de gergelim. As sementes com menor umidade 3,49\% e 5,19\% tiveram a maior porcentagem de sementes dormentes ao final do teste de germinação.
\end{abstract}

Palavras-chave: Sesamum indicum. Teor de água. Osmocondicionamento.

\section{Physiological quality of sesame seeds in function of balance in different hygroscopic salts}

\begin{abstract}
The present work aimed to evaluate the physiological quality of sesame seeds after their hygroscopic balance under different conditions of relative humidity. The research was carried out at the UNEMAT Phytotechnics Laboratory, Cáceres-MT and at the Central Seed Laboratory at the Federal University of Lavras, Lavras-MG. Sesame seeds from the cultivar BRS Seda were used, and to achieve hygroscopic balance salts were used that provided different humidity. The water content of the seeds was determined by the greenhouse method, with 2 repetitions of 2 grams germination was carried out in 4 repetitions of 50 seeds per treatment, while the other evaluations, electrical conductivity tests and tetrazolium, were conducted with 4 repetitions of 25 seeds per treatment. The design used was completely randomized with five treatments, where the means were compared using the Scott-Knott test at 5\%. It can be seen that there was no difference in germination and electrical conductivity for the proposed treatments, demonstrating that the seeds had a similar quality with regard to the integrity of their membranes. The $3.49 \%$ and $19.37 \%$ humidity favor the viability of sesame seeds. The seeds with the lowest humidity $3.49 \%$ and $5.19 \%$ had the highest percentage of dormant seeds at the end of the germination test.
\end{abstract}

Keywords: Sesamum indicum. Water content. Osmopriming

\section{INTRODUÇÃO}

O gergelim (Sesamum indicum L.) é a mais antiga oleaginosa conhecida, tendo como centro de origem a África, onde se concentra a maioria das espécies silvestres do gênero Sesamum (LIMA et al., 2013).

Essa espécie, de distribuição tropical e subtropical, é resistente à seca e possui ampla adaptabilidade em condições adversas de clima e solo, por outro lado, é extremamente sensível à salinidade e à alcalinidade (GRILO JÚNIOR E AZEVEDO, 2013).

A Semente de gergelim contém índices elevados de óleo (46\% a 50\%) com 83\% a 90\% de ácidos graxos saturados, $20 \%$ de proteínas e vários nutrientes menores como as vitaminas e minerais. Desta forma, as sementes de gergelim possuem elevadas quantidades de componentes nutricionais, muito utilizados em tratamentos na área da saúde, com efeitos anti-hipertensivos, anticancerígenos, anti-inflamatórios e antioxidantes (PATHAK et al., 2014).

Como já foi mencionado, as sementes dessa espécie contêm óleo de excelente qualidade, o que ampliam as possibilidades econômicas da utilização do gergelim. Com o recente incentivo do governo Federal, em utilizar o biodiesel na matriz energética nacional, as oleaginosas surgem como fonte de energia renovável com a finalidade de preservação do meio ambiente (MESQUITA et al., 2013).

Desta forma, a cultura do gergelim vem assumindo grande importância econômica no território brasileiro, notadamente em sistemas agrícolas familiares. Para garantir o aumento da produtividade agrícola, um dos aspectos a serem considerados é o uso de sementes de alta qualidade, que podem ser avaliadas por meio do seu potencial fisiológico, sendo esta característica imprescindíveis

Recebido em 11/03/2020; Aceito para publicação em 08/04/2021

${ }^{1}$ Universidade do Estado do Mato Grosso

*email: tanismaresilva@unemat.br 
para que as plantas possam expressar todo o seu potencial e elevar o rendimento final da cultura (ZUCARELI et al., 2015).

As sementes, de modo geral, possuem capacidade de perder ou ganhar água, em razão da umidade relativa do ar, ou seja, quantidade de vapor d'água do ar que a circunda, a uma determinada temperatura. Com isso, o equilíbrio higroscópico ocorre sempre que a umidade dos grãos e/ou sementes fica em equilíbrio com a umidade relativa do ar a uma mesma temperatura, e esse equilíbrio é uma característica importante para o armazenamento (BORDIGNON, 2009).

O osmocondicionamento é uma técnica de embebição controlada das sementes, que visa obter uma germinação mais rápida e homogênea, mesmo sob estresse, conhecida também como priming. Agentes osmóticos inorgânicos como o $\mathrm{NaCl}, \mathrm{KCl}$ e KI, e orgânicos como polietilenoglicol (PEG), manitol e sacarose, são utilizados para aumentar a concentração da solução, diminuindo desta forma, o potencial hídrico da mesma (KISSMANN et al., 2010).

Entretanto, muitos são os fatores que determinam esse sucesso, como a qualidade inicial das sementes, a temperatura, o potencial osmótico da solução e o agente osmótico utilizado (PEREIRA et al. 2008).

$\mathrm{O}$ teor de água em sementes de gergelim é um fator importante quando se pretende armazenar, ou até mesmo, para o estabelecimento da cultura, sendo este um dos responsáveis pela qualidade fisiológica das sementes e por seu processo de deterioração. Entre os métodos de averiguação da qualidade em sementes, destacam-se o teste de germinação, condutividade elétrica e tetrazólio por sua efetividade e rapidez.

A germinação das sementes envolve uma sequência ordenada de eventos metabólicos que resulta na formação da plântula. Dentre os fatores ambientais que afetam o processo de germinação destacam-se a temperatura, luz, disponibilidade de oxigênio e de água. Quando estes fatores são otimizados, as sementes expressam o seu potencial máximo de germinação, característica importante para se obter um estabelecimento rápido e uniforme das plântulas em campo (CARVALHO, NAKAGAWA, 2000).

De acordo com Kulczynski et al. (2014), o teste de condutividade elétrica apresenta algumas vantagens, entre elas o baixo custo e a rapidez na obtenção dos resultados. Esse teste baseia-se na integridade da membrana das sementes, que é o que determina seu vigor, desta forma quanto maior a quantidade de lixiviados na água de embebição, maior será a degradação das membranas e menor será o vigor da semente.
Outra metodologia utilizada para avaliação rápida da qualidade das sementes é o teste de tetrazólio, no qual os resultados podem ser obtidos em menos de 24h. Esse teste fundamenta-se na alteração da coloração dos tecidos da semente na presença de uma solução de sal de tetrazólio. A coloração resultante da reação é uma indicação positiva da viabilidade através da detecção da respiração a nível celular. Tecidos mortos não reagem e consequentemente não são coloridos (FRANÇA NETO, KRZYZANOWSKI, 1998).

Tendo por base as diversas finalidades do uso das sementes de gergelim, atendendo desde a indústria de panificação até a de produção de biodiesel, viu-se a necessidade de expandir conhecimento a respeito desta oleaginosa rica em óleo e proteínas que está em constante desenvolvimento no Brasil. Assim, o presente trabalho teve por objetivo avaliar a qualidade fisiológica de sementes de gergelim após seu equilíbrio higroscópico em diferentes condições de umidades relativas condicionadas em água, acetato de potássio, iodeto de potássio, cloreto de sódio e cloreto de potássio.

\section{MATERIAL E MÉTODOS}

O trabalho foi desenvolvido no Laboratório de Fitotecnia do Departamento de Agronomia da UNEMAT, Cáceres-MT e no Laboratório Central de Sementes na Universidade Federal de Lavras, LavrasMG. Foram utilizadas sementes de gergelim do cultivar BRS Seda, cedidas pela Embrapa Algodão.

As sementes com umidade inicial de 5,19\% foram submetidas a condições de diferentes umidades relativas, até obter o equilíbrio higroscópico. Para garantir a umidade relativa desejada, foi adicionado 100 gramas de sal dentro de potes de vidro com capacidade de $500 \mathrm{ml}$, e umedecido com água destilada, até obter uma solução salina saturada capaz de controlar a umidade relativa em seu interior, e um vidro contendo somente água.

As sementes foram devidamente pesadas e colocadas em pacotes permeáveis e inseridas dentro do vidro, sem entrar em contato com a solução salina saturada, posteriormente o pote foi tampado e acondicionadas em estufa incubadora Demanda Bioquímica de Oxigênio (BOD) a $25{ }^{\circ} \mathrm{C}$, com fotoperíodo de 12 horas.

A testemunha consistia de sementes que não passaram por nenhum condicionamento higroscópico. O tratamento que proporcionou a umidade relativa de $23 \%$ consistia de 100 gramas de acetato de potássio. Em outro pote as sementes foram expostas a umidade relativa de $68 \%$ proporcionada pelo iodeto de potássio até atingir o equilíbrio higroscópico, para posterior exposição a umidade relativa de $75 \%$ obtida através do cloreto de sódio. 
Por fim, para que a semente ganhasse água gradativamente, foram submetidas aos sais iodeto de potássio (68\% UR), cloreto de sódio ( $75 \%$ UR) e cloreto de potássio ( $85 \%$ UR), de modo que a porção de sementes ficou no pote que proporcionava a umidade relativa respectiva de cada sal até entrar em equilíbrio higroscópico.

Vale ressaltar que as sementes não entraram em contato com os sais e a água, elas apenas ficaram expostas a umidade relativa que cada tratamento proporcionava.

Para o controle da umidade, foram realizadas pesagens, duas vezes ao dia, até que fosse obtido o peso constante das sementes. Após o equilíbrio higroscópico das sementes, foram obtidos os teores de água conforme tabela 1.

Tabela 1. Teores de água das sementes de gergelim após equilíbrio higroscópico em temperatura constante de $25^{\circ} \mathrm{C}$

\begin{tabular}{cc}
\hline Tratamento & Umidade \\
Testemunha & $5,19 \%$ \\
Acetato de Potássio (23\% UR) & $3,49 \%$ \\
Iodeto de Potássio (68\% UR) e Cloreto de Sódio (75\% UR) & $6,33 \%$ \\
Iodeto de Potássio, Cloreto de Sódio e Cloreto de Potássio (85\% UR) & $7,75 \%$ \\
Água (100\% UR) & $19,37 \%$ \\
\hline
\end{tabular}

As sementes foram ganhando água gradativamente, de modo que as que apresentavam umidade inicial de $5,19 \%$ passaram num primeiro momento pelo Iodeto de Potássio, até atingir o equilíbrio higroscópio, em seguida pelo Cloreto de Sódio, onde chegou a 6,33\% de teor de água. No outro tratamento, as sementes com $6,33 \%$ de água foram submetidas ao sal Cloreto de Potássio, onde atingiu o teor de água de $7,75 \%$. Outro fato importante é que a temperatura influência diretamente na umidade que o sal vai proporcionar as sementes, sendo que neste caso a temperatura utilizada foi de $25^{\circ} \mathrm{C}$.

Após obtenção das umidades, foram realizados testes para a avaliação da qualidade destas sementes, sendo estes: germinação, condutividade elétrica e tetrazólio. O delineamento utilizado foi inteiramente casualizado com cinco tratamentos, onde as médias foram comparadas por meio do teste de Scott-Knott a $5 \%$.

Teor de água: Foram utilizadas duas repetições de aproximadamente 2,0 gramas de sementes e determinado pelo método da estufa a $105^{\circ} \mathrm{C}$ por 24 horas (BRASIL, 2009). Os resultados foram expressos em porcentagem com base no peso úmido das sementes.

Teste de Germinação: Conduzido em quatro repetições de 50 sementes por tratamento, distribuídas em caixas tipo gerbox $(11,0$ x 11,0 x 3,5 $\mathrm{cm})$, sobre duas folhas de papel mata-borrão, umedecidas com água destilada equivalente a 2,5 vezes o peso do substrato seco, mantidas em BOD a $25{ }^{\circ} \mathrm{C}$ e fotoperíodo de doze horas. As avaliações foram realizadas no terceiro e no sexto dia após a semeadura, de acordo com os critérios estabelecidos pelas Regras para análise de sementes (BRASIL, 2009).
Condutividade elétrica: As avaliações foram conduzidas com quatro repetições de 25 sementes por tratamento, previamente contadas e pesadas (precisão de $0,0001 \mathrm{~g}$ ), imersas em $75 \mathrm{ml}$ de água destilada, na temperatura de $25^{\circ} \mathrm{C}$ por um período de 2 horas conforme descrito por Kulcznski et al. (2014). Decorrido este período, a condutividade da solução foi determinada com o uso de um condutivímetro modelo ADAMO, sendo este resultado dividido pelo peso de cada subamostra, expressos em $\mu \mathrm{S} \mathrm{cm}^{-1} \mathrm{~g}^{-1} \mathrm{de}$ sementes.

Teste de Tetrazólio: Ao final do teste de germinação, as sementes não germinadas foram submetidas ao teste de tetrazólio para verificação da dormência. Foram utilizadas quatro repetições de 25 sementes para cada tratamento. Inicialmente as sementes foram pré-condicionadas em papel mata-borrão umedecido com 2,5 vezes o peso do papel. Posteriormente, foi realizado corte das sementes na região distal ao eixo embrionário e corte longitudinal no maior sentido, e apenas uma metade da semente foi utilizada. Em seguida, as sementes foram submersas em sal de tetrazólio a $0,5 \%$ por três horas e mantida em BOD a $30^{\circ} \mathrm{C}$. As sementes foram classificadas em viáveis ou inviáveis segundo a categorização proposta por JESUS et al., (2015).

\section{RESULTADOS E DISCUSSÕES}

Pode-se observar que não houve diferenças significativas nos valores de germinação para os tratamentos propostos, constatando, assim, que as sementes de gergelim toleram tanto a secagem quanto o aumento gradativo do seu teor de água (Tabela 2). 
Tabela 2. Resultados médios de teor de água (TA), germinação (G), sementes dormentes (SD), Teste de Tetrazólio (TZ) e condutividade elétrica (CE).

\begin{tabular}{|c|c|c|c|c|c|}
\hline \multirow{2}{*}{ Tratamentos } & TA & $\mathbf{G}$ & SD & $\mathbf{T Z}$ & $\mathbf{C E}$ \\
\hline & \multicolumn{4}{|c|}{$\%$} & $\mu \mathrm{S}$ \\
\hline Testemunha & 5,19 & $58 \mathrm{a}$ & $57 \mathrm{a}$ & $32 \mathrm{~b}$ & $75,44 \mathrm{a}$ \\
\hline Acetato de Potássio & 3,49 & $57 \mathrm{a}$ & $39 a$ & $61 \mathrm{a}$ & $81,35 \mathrm{a}$ \\
\hline Cloreto de Sódio & 6,33 & $65 \mathrm{a}$ & $26 \mathrm{~b}$ & $39 \mathrm{~b}$ & $80,60 \mathrm{a}$ \\
\hline Cloreto de Potássio & 7,75 & $59 a$ & $26 \mathrm{~b}$ & $55 \mathrm{~b}$ & $84,41 \mathrm{a}$ \\
\hline Água & 19,37 & $53 \mathrm{a}$ & $18 \mathrm{~b}$ & $58 \mathrm{a}$ & $85,29 \mathrm{a}$ \\
\hline $\mathrm{CV}(\%)$ & & 9,28 & 39,04 & 24,87 & 10,10 \\
\hline
\end{tabular}

As médias seguidas pela mesma letra na coluna, não diferem entre si pelo teste Scott-Knott a 5\% de probabilidade.

Vale ressaltar que a utilização de sais promove uma umidade relativa no interior do recipiente e as sementes perdem ou ganham água em função da sua umidade inicial e do equilíbrio higroscópico.

Sementes consideradas ortodoxas toleram dessecação a baixos teores de água, o que pode ser observado quando as sementes de gergelim com umidade inicial de 5,19\% foram secadas até a umidade de 3,49\%. Conforme Villela (2009), a longevidade das sementes ortodoxas pode ser acentuadamente prolongada pela secagem até teores de água de 5 a $8 \%$ e acondicionadas em embalagens impermeáveis.

Ao final do teste de germinação, as sementes não germinadas foram submetidas ao teste de tetrazólio para verificação da dormência. Pode-se observar que as sementes secadas em Acetato de Potássio (UR $23 \%$ ) e a testemunha tiveram a maior porcentagem de sementes dormentes (Figura 1).
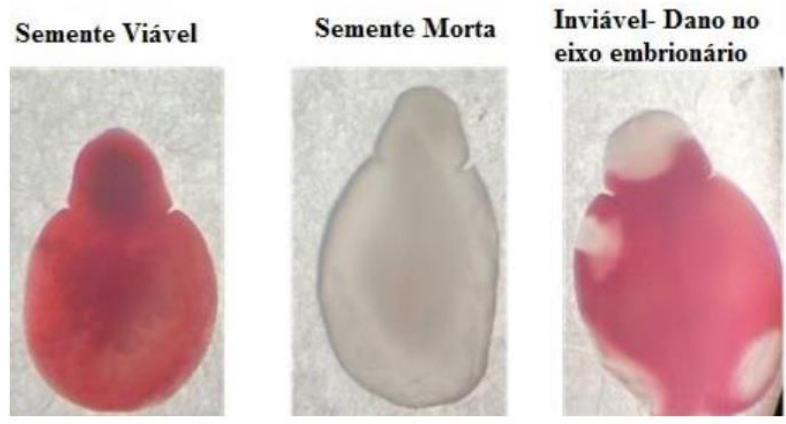

Figura 1. Sementes de gergelim viável, inviável e morta avaliadas pelo teste de tetrazólio.

Os valores obtidos no teste de condutividade elétrica para as sementes com diferentes teores de água não diferiram entre si, demonstrando que mesmo sementes com umidade inferior a $5 \%$ a quantidade de lixiviados foi semelhante aquelas com umidade de 19,37\%, inferindo que o sistema de membrana não foi prejudicado com baixa umidade. $\mathrm{O}$ fato da semente ganhar ou perder água gradativamente, garantiu que a integridade de sua membrana fosse preservada.

De acordo com Oliveira e Filho (2011), as respostas ao osmocondicionamento variam em função da espécie, do vigor e da qualidade do lote das sementes e do período de embebição das mesmas na solução osmótica.

Quando as sementes ganham água, adquirem a capacidade de regeneração de suas membranas reparando os danos químicos, físicos e biológicos que possam tê-la afetado, influenciando diretamente a quantidade de lixiviados liberados para o meio externo, ou seja, quanto mais rápida e bem sucedida for a regeneração das membranas quando submetidas ao processo de absorção de água, menor será a perda de lixiviados da semente para o meio externo, mantendo assim um maior vigor das sementes (VIEIRA, KRZYZANOWSKI, 1999).

As sementes com teores de água mais elevados proporcionaram sementes com maior índice de viabilidade, com exceção as sementes submetidas ao Acetado de Potássio (3,49\%), que mesmo diminuindo seu teor de água, garantiu índices satisfatórios de viabilidade, de acordo com o teste de tetrazólio.

\section{CONCLUSÃO}

1. A mudança de umidade relativa não interferiu na qualidade fisiológica das sementes. .

2. As umidades $3,49 \%, 7,75 \%$ e $19,37 \%$ favorecem a viabilidade das sementes de gergelim.

3. As sementes com menor umidade $3,49 \%$ e $5,19 \%$ tiveram a maior porcentagem de sementes dormentes ao final do teste de germinação.

\section{REFERÊNCIAS}

BRASIL. Regras para análise de sementes. Ministério da Agricultura, Pecuária e Abastecimento. Brasília: Mapa/ACS, 2009. 399 p. 
BORDIGNON, B. C. S. Relação das condições de armazenamento com a qualidade fisiológica de sementes e composição do óleo extraído de cultivares de soja. 2009. 90f. Dissertação (Mestrado em Produção Vegetal) - Universidade Federal de Santa Maria, Santa Maria.

CARVAlHO, N. M. e NAKAGAWA, J. Sementes: ciências, tecnologia e produção. 2.ed. Campinas: Fundação Cargill, 2000. 565p.

FRANÇA NETO, J.B.; KRZYZANOWSKI, F.C.; COSTA, N.P. O teste de tetrazólio e sementes de soja. Londrina: EMBRAPA-CNPSo, 1998. 72p.

GRILO JÚNIOR, J. A. S.; AZEVEDO, P. V. de. Crescimento, desenvolvimento e produtividade do gergelim 'BRS Seda' na agrovila de Canudos, em Ceará Mirim (RN). Revista Holos, v.2, p.19-33, 2013.

JESUS, L. L.; NERY, M. C.; ROCHA, A. S.; MELO, S. G. F.; CRUZ, S. M.; DIAS, D. C. F. S. Teste de tetrazólio para sementes de Sesamum indicum. Revista de Ciências Agrárias, v. 38, p.422-428, 2015.

KISSMANN, C.; SCALON, S. P. Q.; MOTA, L. H. S.; VIEIRA, M. C. Germinação de sementes de Stryphnodendron Mart. Osmocondicionadas. Revista Brasileira de Sementes, v. 32, no 2 p. 026-035, 2010.

KULCZYNSKI, S. M.; MACHADO, E. C.; BELLÉ, C.; SANGIOGO, M.; KUHN, P. R.; SORATTO, R. P. Teste de Condutividade Elétrica para Avaliação da Qualidade Fisiológica de Sementes de Gergelim (Sesanun indicum L.). Revista Agrarian. Dourados, v.7, n.23, p.72-81, 2014.

LIMA, F. A.; SOUSA, G. G; VIANA, T. V. A.; PINHEIRO NETO, L. G.; AZEVEDO, B. M.; CARVALHO, C. M. Irrigação da cultura do gergelim em solo com biofertilizante bovino. Revista Brasileira de Agricultura Irrigada, v.7, p.102-111, 2013.

MESQUITA, J.B.R.; AZEVEDO, B.M.; CAMPELO, A.R.; FERNANDES, C.N.V. E VIANA, T.V.A. Crescimento e produtividade da cultura do gergelim (Sesamum indicum L.) sob diferentes níveis de irrigação. Revista Irriga, vol.18, n.2, p. 364-375, 2013.
OLIVEIRA, A. B., FILHO, E. G. Estabelecimento de plântulas de sorgo oriundas de sementes osmocondicionadas de diferentes qualidades fisiológicas. Revista Brasileira de Ciências Agrárias, v.6, p. 223-229, 2011.

PATHACK, N.; RAI, A.K.; KUMARI, R.; THAPA A.; and BHAT, K.V. Sesame Crop: An underexploited Oilseed Holds Tremendous Potential for Enhanced Food Value. Agriculture Sciences, v.5, p. 519-529, 2014.

PEREIRA, M. D., DIAS, D. C. F. S., DIAS, L. A. S. \& ARAUJO, E. F. Germination and vigor of carrot seeds primed in moistened paper and aerated solution. Revista Brasileira de Sementes, v. 30, p. 137-145, 2008.

VIEIRA, R.D.; KRZYZANOWSKI, F.C. Teste de condutividade elétrica. In: VIEIRA, R.D.; KRZYZANOWSKI, F.C.; FRANÇA NETO, J.B. (Ed.). Vigor de sementes: conceitos e testes. Londrina, PR: ABRATES, p.1-26, 1999.

VILLELA, F.A. O potencial de armazenamento de cada semente. Seed News, 2009. Disponível em:<http://seedsnews.inf.br/_html/site/content/repor tagem_capa/impimir.php?id=31>. Acesso em $22 \mathrm{de}$ Agosto de 2016.

ZUCARELI, C., BRZEZINSKI, C. R., ABATI, L., WERNER, F., RAMOS JUNIOR, E. U., NAKAGAWA, J. Qualidade fisiológica de sementes de feijão carioca armazenadas em diferentes ambientes. Revista Brasileira de Engenharia Agrícola e Ambiental, Campina Grande, v.19, n.8, p.803-809, 2015. 